\title{
Spending adaptation money wisely
}

\author{
Samuel Fankhauser and Ian Burton
}

January 2011

Centre for Climate Change Economics and Policy

Working Paper No. 47

Grantham Research Institute on Climate Change and the Environment

Working Paper No. 37 
The Centre for Climate Change Economics and Policy (CCCEP) was established by the University of Leeds and the London School of Economics and Political Science in 2008 to advance public and private action on climate change through innovative, rigorous research. The Centre is funded by the UK Economic and Social Research Council and has five inter-linked research programmes:

1. Developing climate science and economics

2. Climate change governance for a new global deal

3. Adaptation to climate change and human development

4. Governments, markets and climate change mitigation

5. The Munich Re Programme - Evaluating the economics of climate risks and opportunities in the insurance sector

More information about the Centre for Climate Change Economics and Policy can be found at: http://www.cccep.ac.uk.

The Grantham Research Institute on Climate Change and the Environment was established by the London School of Economics and Political Science in 2008 to bring together international expertise on economics, finance, geography, the environment, international development and political economy to create a worldleading centre for policy-relevant research and training in climate change and the environment. The Institute is funded by the Grantham Foundation for the Protection of the Environment, and has five research programmes:

1. Use of climate science in decision-making

2. Mitigation of climate change (including the roles of carbon markets and lowcarbon technologies)

3. Impacts of, and adaptation to, climate change, and its effects on development

4. Governance of climate change

5. Management of forests and ecosystems

More information about the Grantham Research Institute on Climate Change and the Environment can be found at: http://www.Ise.ac.uk/grantham.

This working paper is intended to stimulate discussion within the research community and among users of research, and its content may have been submitted for publication in academic journals. It has been reviewed by at least one internal referee before publication. The views expressed in this paper represent those of the author(s) and do not necessarily represent those of the host institutions or funders. 


\title{
Spending Adaptation Money Wisely
}

\author{
Samuel Fankhauser ${ }^{\mathrm{a}}$ and lan Burton ${ }^{\mathrm{b}}$
}

December 2010

\begin{abstract}
The discussions about adaptation finance have mostly been about process: how money should be raised and how adaptation spending should be governed and monitored. This paper seeks to move the focus of the debate back towards the substance of adaptation by asking what "good adaptation" in developing countries would look like. We argue that the best use of funds in the short term may be for "soft", or less tangible developmental activities that increase adaptive capacity. Building a minimum level of adaptive capacity everywhere is central to efficient, effective and equitable adaptation and yields immediate benefits irrespective of future climate regimes. We discuss a number of operational challenges in delivering this kind of adaptation, including a preoccupation with additionality - which makes the integration of adaptation and development harder - and a preference for "concrete" and more readily visible adaptation projects. We leave open the question of whether and how the adaptation regime that is emerging from the Cancun Agreements will be able to deliver wise adaptation decisions, but our analysis recognizes that further institutional development is required.
\end{abstract}

Keywords: adaptation finance, climate change and development, economic efficiency

Acknowledgements: We are grateful to Alex Bowen, Thea Dickinson, Su-Lin Garbett-Shiels, Erik Haites, Kirk Hamilton, Ian Rowlands, Guido Schmidt-Traub, Joel Smith and John Ward for their comments and suggestions. Fankhauser also acknowledges financial support by the Grantham Foundation for the Protection of the Environment, as well as the Centre for Climate Change Economics and Policy, which is funded by the UK Economic and Social Research Council and Munich Re.

\footnotetext{
${ }^{a}$ Grantham Research Institute and Centre for Climate Change Economics and Policy, London School of Economics.

${ }^{b}$ University of Toronto and, International Institute for Environment and Development.
} 


\section{Introduction}

The debate about climate change finance so far has been as much about trust as it has been about finance - or more accurately, about the lack of trust. The protracted Convention negotiations under the Bali Action Plan (agreed in December 2007) have devoted much time and energy to the discussion of process: how funds should be raised, through which channels they should be disbursed, how spending decisions should be governed and, above all, how activities are to be monitored, reported and verified. This preoccupation with monitoring and governance is a direct reflection of the low and the apparently declining level of trust among and between the Parties to the Convention. To what extent this decline in trust has been reversed by the Cancun Agreements remains to be seen, although appears to be grounds for some cautious optimism. Lack of trust can be traced back, among other factors, to a string of donor promises of financial support that have not been fully met or were long delayed, and to a lack of confidence among donors in the reliability of some developing countries in managing funds.

The process questions are important. Adaptation to climate change will require substantial amounts of money (UNFCCC 2007; World Bank 2010a; Narain 2011; Fankhauser 2010), and funding is starting to become available. The World Bank reckons that $\$ 2.2-2.5$ billion in adaptation finance has so far been committed (World Bank 2010b). This could be topped up with a portion of the $\$ 30$ billion in fast-start funding pledged in Copenhagen at the end of 2009 and a share of the annual $\$ 100$ billion in climate finance promised by 2020 (see AGF 2010). In light of these magnitudes, getting the process right is critical.

The decision at COP 16 to establish the Green Climate Fund under the guidance of the COP is generally seen as a step in the right direction. The Board with 12 members each from developed and developing countries with the latter group to include seats for the Least Developed Countries (LDCS) and Small Island Developing States (SIDS). A Transitional Committee with a developing country majority will design the Green Climate Fund during 2011.The World Bank will act as interim trustee for the Fund, subject to review three years after the operationalization of the Fund. These encouraging developments leave open many questions about how the Fund, as well as other channels of investment in adaptation will work to ensure successful adaptation.

There is a danger that instead of getting on with the urgent tasks of adaptation the Parties will become increasingly embroiled in debates about governance, monitoring and additionality. It will be unfortunate and counter-productive if these concerns are allowed to overwhelm equally or more important questions relating to the efficient, effective and 
equitable use of funds. To a large extent, the decision on adaptation priorities belongs to national governments. However, nothing is likely to undermine progress on adaptation in the developing countries more than evidence, or even suspicion, that the funds are being diverted or used wastefully, and are not reaching those most in need of assistance.

In this paper we seek to move the focus of the debate away from process issues and back towards the substance of adaptation. We try to answer the question of what "good adaptation" in developing countries might look like, and what kind of adaptation measures should therefore be financed as a priority.

Stern $(2008,2009)$ defines "good" adaptation as meeting three criteria: It is efficient in the sense that it achieves results at the lowest possible cost. It is effective in keeping down the negative impacts of climate change, and it is equitable by targeting the countries and population groups most worthy of assistance. ${ }^{1}$ Bird and Brown (2010) highlight timeliness, appropriateness, national ownership and focus on the most vulnerable.

It is hard to disagree with these high-level criteria and indeed they are not unique to adaptation spending. Similar criteria are also core principles for the allocation of concessional development assistance, for example. Development agencies like the World Bank use them to ensure scarce grant resources are spent wisely and fairly (see e.g. IDA 2007). ${ }^{2}$

However, in practice the need for efficiency, effectiveness and equity poses some quite complex operational challenges that adaptation institutions may find difficult to address. The paper reviews the most important of them. In concrete terms they have to do with the integration of adaptation and development, the identification of adaptation priorities in the face of uncertainty and the balance between "hard", structural adaptation and "soft", behavioral measures. And aggravating them all is the sheer scale and scope of the adaptation problem.

We do not seek to answer the question whether the adaptation regime that is emerging post-Cancun is able to address these challenges and is, in that sense, fit for purpose. Other authors have written extensively about the design of adaptation institutions (e.g., Müller 2010, Müller and Gomez-Echeverry 2009), although they do not directly answer this

\footnotetext{
${ }^{1}$ See Adger et al (2006) for a more detailed discussion of equity issues in adaptation.

2 Mirroring the IDA process, Barr et al (2010) and World Bank (2010b) propose efficiency, equity and transparency as the main criteria of the allocation process. Note, however, that they refer to the process of fund allocation, which is different from the adaptation outcomes that Stern is concerned about.
} 
particular question either. It is not easy to predict with confidence the shape of the future regime and to assess how fit for purpose it will be in the face of multiple forces and stresses.

We do note, though, that the track record of existing adaptation institutions is not without blemish $^{3}$ and that the emerging adaptation regime appears to be the result of institutional turf battles as much as thoughtful design. It is clear therefore, that the delivery arrangements for adaptation will be further developed and revised and that these developments should be continually debated and scrutinised both within and outside the Convention process. This paper is a contribution to such debate and scrutiny. We hope that the characterisation of "good" adaptation we attempt in this paper, and of the operational challenges that follow from it, will be helpful in informing the process.

The paper starts, in section 2, with an exploration of generic priorities for "wise" adaptation. Setting adaptation priorities has mainly been seen as a location-specific exercise that requires detailed knowledge of local circumstances and place-to-place variations in climate risk. Nevertheless, as we will see in section 2, the literature on adaptation economics, decision making under uncertainty, and adaptation and development can offer some broad pointers on adaptation priorities and measures that are likely to be important independent of local circumstances. There has been a move away from a strictly place-based view of adaptation towards the recognition of the need for more programmatic, strategic, and even "transformational" approaches.

Armed with this knowledge we ask, in section 3, what operational challenges adaptation institutions may face in delivering on those generic priorities. Section 4 concludes with suggestions on what this might mean for the emerging adaptation regime.

\section{Adaptation priorities}

How to spend adaptation money wisely is at its core a classic economic problem of resource allocation. There are well-established techniques that can be brought to bear on such problems, such as cost-benefit analysis, cost-effectiveness analysis and multi-criteria analysis. However, adaptation to climate change is a much more complex issue than the typical resource allocation problem and requires different approaches to the standard appraisal techniques.

\footnotetext{
${ }^{3}$ See for instance Anderson et al (2009), Klein and Möhner (2009) and Osman-Elasha and Downing (2007)
} 
Adaptation is a complex problem for many reasons, but three features in particular stand out (Ranger et al 2010; Fankhauser et al 1999):

- the intricate link between adaptation and other socio-economic trends, such as economic growth and development (for example there is much debate about the difference between adaptation to climate change, and adaptation to multiple stressors)

- the pervasiveness and temporal complexity of adaptation decisions (for example the need to harmonise or integrate adaptation across spatial and temporal scales) and

- the high level of uncertainty about local climate outcomes (for example the uncertainty about the balance between increased temperature and increased rainfall in terms of potential evapotranspiration in specific localities).

The reasons why adaptation is complex contain lessons about what the immediate adaptation priorities should be. We discuss them in the rest of this section. The focus is on identifying generic priority projects and programmes, while bearing in mind the localised nature of many adaptation decisions (on country priorities see Barr et al 2010).

\section{Adaptation and development}

Adapting to climate conditions is one of the oldest challenges of mankind (Lamb 1988), and human populations and societies have been remarkably successful in coping and adapting to climate over many generations. Globally speaking climate varies more over space than over time. Human populations have been able to live successfully in a wide variety and range of climates. However, adaptation is not and never has been perfect. Fluctuations in climate variables cause billions of dollars of damages each year and cost countless lives. Some of these losses are the result of a deliberate economic calculus: residual risks were accepted because they were too expensive to avoid. In other cases, however, losses are the consequence of insufficient adaptation or maladaptation.

Cases of maladaptation can be found in many circumstances, but insufficient adaptation - or an "adaptation deficit", (Burton 2009) - is often linked to underdevelopment and to deficiencies in choices (Burton 2010). There is both empirical and anecdotal evidence that the effects of climate events are particularly severe on poor people. Empirical work on climate variation by Dell et al (2008) identified a raft of negative climate effects in lowincome countries: annual temperature spikes are associated with lower rates of economic growth, lower industrial and agricultural output, lower investment and greater political instability. However, no such effects were found in high-income countries. Raddatz (2009) 
found that the GDP effect of a given climate disaster is twice as high in low-income countries as in middle-income, which in turn suffer twice as much as high-income countries.

The link between climate and economic development was further unpacked by Noy (2009), who related the adverse effects of climate disasters to basic development indicators like income per capita, literacy, the quality of institutions, trade openness and the depth of financial markets. Barr et al (2010) and Brooks et al (2005) used a similar set of indicators to measure adaptive capacity, which is a determining factor of vulnerability.

Development, or lack thereof, is thus a critical aspect of vulnerability to climate change, and therefore of adaptation. However, we know little about how these various development indicators combine to affect vulnerability. Tol and Yohe (2007) conjecture that climate impacts are determined by the aspect of adaptive capacity that is least developed or, as they call it, by the weakest link. In other words, weakness in one area (say, poor institutions) cannot be fully compensated by strength in another (say, good climate information). This suggests that adaptation to climate change cannot be considered as one policy issue but many. It must also account for the development context and for gaps in existing capacity (e.g. in terms of developing planning, location and relocation issues, insurance, infrastructure codes and standards and their enforcement, agriculture policies and practices, water and public health management and so forth).

McGray et al (2007) identified a sequence of measures, both developmental and adaptation that together would reduce vulnerability to climate change (see also Klein and Persson 2008). They were grouped into four categories:

- Measures that reduce vulnerability to stress more broadly (whether climate-related or not), including fundamental development objectives like health, sanitation and poverty eradication;

- Creation of "response capacity", such as resource management practices, planning systems and effective public institutions;

- The management of current climate risks, including flood and drought prevention, and disaster risk reduction and management.

- Policies specifically addressing anthropogenic climate change, such as accelerated sea level rise and an increased incidence of extreme weather events.

In the light of this evidence it seems reasonable to promote basic development and growth policies like health, sanitation, primary education and institutional development as a priority for adaptation. Indeed, Vivid Economics (2010) found that most of the policies development 
agencies adopt to promote economic growth do in fact reduce vulnerability to climate change. There are important exceptions, though, such as accelerated development in highrisk areas and excessive reliance on vulnerable products, such as water-intensive crops. Similarly, developing countries have huge infrastructure needs and these investments should be adapted to climate change from the outset.

The type of development that is being promoted thus clearly matters, but in general economic development of the "right kind" seems a good way of starting to reduce vulnerability to climate change, a claim made earlier by Schelling $(1992,1997)$.

\section{Timing and scope}

Even if society were perfectly adapted to today's climate, preparing for climate change would still be a major challenge. Our response to prevailing climate conditions is ingrained in most areas of human activity and the majority of them will require some degree of adjustment, including agricultural practices, building codes, location decisions and the design of infrastructure and changes in the demand for energy and water. The adjustments required even for modest climate change are therefore wide-ranging and potentially substantial.

However, not all adaptation decisions have to be made at once. Adaptation is a long-term process. Some measures have to be taken now, but getting the adaptation timing right is a major challenge (Fankhauser et al 1999 and Hallegatte 2009).

Fankhauser et al. (1999) analyse adaptation timing in a simple economic model that compares the net benefits of adaptation now or later (see also Agrawala and Fankhauser 2008). The comparison of the two cost-benefit streams reveals three main differences between early and late adaptation.

First, early action brings forward the cost of adaptation. This normally imposes a cost penalty, since future costs can be discounted. However, sometimes early adaptation is sufficiently cheaper to offset the discounting effect and early action makes sense. One case where this is so are long-lived projects that are hard to reverse. Building adaptation into the design of these investments will often be cheaper than a costly retrofit.

Second, early action brings forward the benefits of adaptation. This is particularly attractive if those early benefits are very high, for example, if a measure yields strong development benefits, or if the benefits would otherwise kick in too late, as in the case of projects that take a long time to bear fruit. 
Third, the long-term benefits of early action may differ from those of delayed adaptation. Delay may result in damages that are impossible to reverse later. For example, sensitive ecosystems like coral reefs may be irretrievably damaged (Carpenter et al 2008).

The conclusion from the Fankhauser et al and Hallegatte studies is that adaptation policy should give precedence to measures that:

- help to prevent costly retrofits later; perhaps the main areas where this will be the case are projects with long lifetimes, such as planning decisions and infrastructure investments;

- have long lead-times and therefore require an early start. Research into new medicines and crops are a good example;

- yield early benefits, such as those that deal with current climate risks, including extreme events, or address current development;

- prevent irreversible loss, such as the protection of fragile ecosystems.

We note that many of the urgent adaptations identified in the previous section also feature on this list of priorities. Efforts to build adaptive capacity in developing countries, which are highlighted in the adaptation and development literature, require considerable lead-time and will yield immediate development benefits regardless of the level and rate of climate change. They are therefore also a priority from the point of view of optimal timing. Similarly spatial planning and economic development plans have the potential (in fact the aim) to create lasting economic structures that may be difficult to reverse later on. It is therefore important that they take climate change into account from the outset.

\section{Uncertainty}

The one factor that, above any others, makes adaptation difficult is the high level of uncertainty about the exact nature and extent of climatic change (Dessai et al 2009; Hallegatte 2009; Ranger et al 2010). There is a high level of confidence in the scientific community about the basic geophysical processes that link emissions to warming, far more than some of the public discussions on climate change would suggest (Solomon et al 2007). However, a lot less is known about how warming will manifest itself at the local level, not just as a change in mean temperature, but also in terms of factors like precipitation, runoff, seasonal patterns, wind speeds and climate extremes. This is the sort of information local decision makers need to fine-tune their adaptation strategies.

Some of this information can be obtained from the downscaling of general circulation models but it is coarse and the levels of uncertainty are high, particularly for precipitation 
and other variables. As a consequence, the accuracy and usefulness of even the most advanced climate models for adaptation decisions has been questioned (Stainforth et al 2007a, b). Adaptation requires decision making under much uncertainty.

Dealing with uncertainty is nothing new for decision makers in other fields, such as finance, and there is a considerable body of literature on the subject (e.g., Gollier 2001). The tools of the decision making trade are increasingly applied to adaptation, and some important insights are emerging. They have been summarized by Ranger et al. (2010), Hallegatte (2009) and Lempert and Collins (2007):

- At its most basic level, uncertainty means that the benefits of adaptation have to be expressed in expected value terms, that is, the probability-weighted mean over the range of possible outcomes;

- If decision makers are risk averse they may put extra weight on negative outcomes, that is, use an expected utility approach and perhaps adopt the precautionary principle;

- If there is a risk of being locked into an undesirable path, decision makers may apply the tools of finance, such as option theory, and put a premium on measures that maintain or increase the flexibility to respond when the true state of nature is revealed;

- Alternatively, they may react to uncertainty by emphasising robustness, that is, adopt designs that function under a wide range of climatic conditions;

- One set of adaptation measures that is attractive in the face of uncertainty are noregrets measures, that is adaptations that are justifiable over a range of climate outcomes.

The above list suggests that uncertainty may alter some of the adaptation priorities identified earlier. The need for robustness and flexibility will affect the adaptation strategy for long-lived investments, for example, certainly in terms of adaptation design and perhaps also in terms of adaptation timing. ${ }^{4}$ However, the essential requirement to factor climate change into long-lived decisions is unaffected.

Elsewhere, climate uncertainty reinforces the priorities identified earlier. Given their winwin nature, the capacity building and hybrid development-adaptation measures emphasised before would fall into this category. The same may be true for many environmental and

\footnotetext{
${ }^{4} \mathrm{An}$ instructive example in this respect is the Thames Estuary (TE) 2100 plan in the UK, which concluded that with suitable alternative measures in place investment into a new flood barrier can be delayed until more is known about climate risk. See http://www.environment-agency.gov.uk/ research/library/consultations/106100.aspx
} 
institutional measures. Agrawala and Fankhauser (2008) note that the call for increased flexibility and robustness applies not just to physical capital, but also to natural and social systems. They mention the sustainable management of natural systems as a way to increase the resilience of ecosystems to a changing climate. Institutionally, Agrawala and Fankhauser argue for regulatory frameworks that encourage individual adaptability and as such increase the flexibility and robustness of economic systems. Both examples are consistent with the indicative priorities identified before.

In sum, the three strands of literature considered here - on adaptation-development links, optimal timing and climate uncertainty - result in a fairly consistent set of adaptation priorities, even though they approach the issue from different analytical directions. We next ask what these priorities imply for adaptation institutions.

\section{Challenges for the Emerging Adaptation Regime}

A look at the current adaptation landscape shows that many of the principles of section 2 are in fact reflected in current adaptation decisions. However, this is probably due to pragmatism as much as to strategic choice. In the absence of substantial adaptation finance, institutions have been limited to providing technical assistance and projects that can be justified by existing development mandates. There is also a certain amount of positioning to secure a role in the emerging adaptation business.

The question is whether the approach to adaptation will change as it is scaled up and finance begins to flow. We see at least two reasons for concern - institutional challenges which, if left unaddressed, could compromise adaptation decisions :

- an inherent preference of adaptation institutions for "hard" structural adaptations, which are more visible and easier to identify than "soft" behavioural or regulatory measures; and

- the difficulty of integrating adaptation and development in an environment where the additionality of adaptation finance has to be unambiguously ascertained.

Exacerbating both challenges is the massive scope of adaptation. The concept of adaptation covers many things, and the limitation of adaptation only to climate change does not in practice reduce the scope very much. "Adaptation" as a stand-alone idea can be used to mean so much, that it tends to lose any specific meaning. To talk about "an adaptation regime "as if it could be some specific reality will increasingly look fanciful. Economic decision making, planning and development will become increasingly inseparable from adaptation and vice versa. 


\section{The current adaptation landscape}

Adaptation is ramping up. Development institutions have begun to integrate adaptation into official development assistance (ODA) and are providing the sort of assistance that will build adaptive capacity, as argued above. In addition, some institutions are preparing themselves to play a role in the management of the additional adaptation financing that has been promised under the Convention, in the Copenhagen Accord and in the Cancun Agreements.

These include the various financial mechanisms related to the Convention including the Global Environment Facility (GEF) and the Adaptation Fund under the Kyoto Protocol. While the Adaptation Fund has only just become operational, the GEF has, through various windows, committed over $\$ 300$ million for adaptation measures already (World Bank 2010b). Most of the 170 projects deal with capacity building and the preparation for adaptation. ${ }^{5}$ Crucially, this includes the preparation of 45 National Adaptation Programmes of Action (NAPAs) for least developed countries. More recently the COP 16 decisions in Cancun, including the decision to create the Green Climate Fund, add to the expected capacity to facilitate adaptation through international mechanisms.

The focus on planning is consistent with the guidance from the UN Framework Convention on Climate Change (UNFCCC), which has restricted the scope for full-blown adaptation projects until now. It is also broadly in line with the priorities identified in section 2, although they would probably justify a more accelerated ramp up of adaptation. The NAPAs themselves also emphasise capacity building and measures with immediate benefits, particularly for agriculture (Agrawala and Fankhauser 2008; Osman-Elasha and Downing 2007). ${ }^{6}$ However, very few NAPA measures have been financed and implemented to date.

It is unclear to what extent future adaptation funds will be allocated through the existing and proposed Convention channels. They have not inspired enough confidence from either donor countries or (in the case of GEF) recipient countries. This does not mean that such funds will be abandoned. They will likely be supported, perhaps even at an increased level, but they are unlikely to be the only delivery channel.

Another set of players are the multilateral development banks, specifically the World Bank Group and the regional development banks. They signaled their wish to play a larger role in managing adaptation funds by setting up the Pilot Programme for Climate Resilience

\footnotetext{
${ }^{5}$ For a full list see www.gefweb.org or www.climatechangefundsupdate.org.

${ }^{6}$ The full list of NAPAs can be found on http://unfccc.int/cooperation support/ least developed countries portal/submitted_napas/items/4585.php.
} 
(PPCR). ${ }^{7}$ One of the strengths of the PPCR is the close integration of adaptation into existing development planning. The small handful of PPCR adaptation strategies that have so far been prepared again emphasise capacity building and win-win measures with early environmental or development benefits (e.g., in terms of agriculture and water management). But they also envisage and the climate proofing of strategic infrastructure assets (see Climate Investment Funds 2010a, b, c). It is not clear to what extent these longterm, structural adaptations will account for uncertainty in the way Ranger et al (2010) and others prescribe (see above).

Donors seem to be willing to allocate a significant share of their new adaptation commitments through the multilateral development banks if potential skill and capacity constraints can be overcome. ${ }^{8}$ Relying on existing development institutions like the multilateral banks is the simplest way of integrating adaptation into development. But donor countries also favour it because it affords them more control over spending decisions. The fact remains that development assistance serves the interests of the donors as well as those receiving assistance. Development assistance, whether for adaptation to climate change or other activities, can be linked to the trade, diplomatic and strategic interests of the donor countries.

There is yet another modality for development assistance - through NGOs and the growing number of civil society organizations that are entering the field of climate-related development. Linking adaptation with community-based development, they have been responsible for some of the most interesting adaptation initiatives to date (Berang-Ford et al. 2010).

\section{Hard and soft adaptation}

There is a well known and long observed practice in adaptation studies to prefer "hard" or "concrete" adaptation measures such as sea walls, dams, irrigation projects, and other infrastructure over "soft" adaptation which includes changes in planning and practices and behavioral changes which are not so visible.

This is partly because the incremental component in hard adaptation is more readily identified and measured as additional, but also because hard responses are easier to identify

\footnotetext{
${ }^{7}$ The PPCR is a part of a $\$ 6.2$ billion set of Climate Investment Funds. It provides programmatic adaptation support worth $\$ 600$ million to nine countries and two multi-country regions (see http://www.climateinvestmentfunds.org /cif/ppcr).

${ }^{8}$ About a quarter of existing adaptation commitments is channelled through multilateral initiatives (World Bank 2010b), primarily the PPCR.
} 
and appraise analytically. Attempts to estimate adaptation costs typically only consider a few alternatives in each sector in order to simplify the estimation of costs, with an emphasis on "hard" structural measures (e.g., Swiss Re 2010; World Bank 2010a). ${ }^{9}$

Yet there is a widely shared view, corroborated by the analysis in section 2, that much effective adaptation can be achieved by relatively low cost changes in practices. Even when hard adaptation is cost-effective it may have to be complemented by soft design or regulatory measures either to minimize costs or avoid moral hazard. Apparently sensible adaptation measures such as dams, dykes, seawalls and flood protection infrastructure of various kinds can have the perverse effect of encouraging development in hazardous areas. Regulatory safe-guards may be required to prevent this. There is a history of unintended consequences and perverse outcomes that is not unique to climate change adaptation.

As we have seen, funding constraints have ensured that dedicated adaptation support to date has mostly been of a preparatory nature - building capacity, identifying priorities, raising awareness - or in other words "soft" adaptation. The question is whether the bias toward hard measures manifest in adaptation analysis will carry over into international adaptation support, once adaptation begins to be funded in earnest. The current adaptation portfolio does not provide conclusive evidence, but the suspicion is that it will, unless some specific steps or provisions are made in the "emerging adaptation regime".

It is conceivable that in institutions with volume pressure, such as the multilateral development banks, the bias towards hard adaptation may persist, despite the long trackrecord and extensive experience of multilateral banks with technical assistance, policy dialogue and sector reform. Hard adaptation may also be favored as larger amounts of funds become available. There are significant transaction costs in project design and loan arrangements. Transaction costs as a proportion of total costs can be more easily reduced when the projects are larger, thus favoring large scale construction projects.

This is clearly a danger under the emerging adaptation regime, although one that can be partially offset by allocation of some funds through different organizations and NGOs. Institutions specializing on capacity building or community-based adaptation, such as NGOs, are more likely to emphasize softer and often more cost-effective adaptation. Such "grass roots" projects may also be more equitable in the sense that there may be more direct access to the poorer and more vulnerable populations.

\footnotetext{
${ }^{9}$ A notable exception is agriculture, where most adaptations concern autonomous farm-level adjustments (Agrawala and Fankhauser 2008).
} 


\section{Dealing with additionality}

If there is one feature that defines the current approach to adaptation it is concern with additionality. There is a strong demand from the developing countries for adaptation to be supported over and above mainstream ODA. Developed countries in turn want to ensure that additional finance is used specifically to reduce vulnerability to climate change, and no other purposes.

Additionality concerns are more likely to be met through a dedicated adaptation institution like the Adaptation Fund under the Kyoto Protocol, where the funds come mainly from the $2 \%$ levy on investments under the Clean Development Mechanism. ${ }^{10}$ The demands for additionality seem less likely to be met if funding is channeled through existing (bilateral or multilateral) development institutions, where it is often difficult to draw a line between adaptation funding for climate change and other development activities.

However, using existing development channels would make it easier for adaptation to be integrated into development. We have seen in section 2 that the boundary between adaptation and development is blurred and that the best way to reduce vulnerability to (current and future) climate events is often through basic development. Indeed the desired direction is to mainstream or integrate adaptation to climate change into development such that all development investments are "climate resilient". Similarly, using a programmatic approach to adaptation (akin perhaps to the PPCR) may be more effective than the projectby-project approach that until very recently has dominated adaptation support.

The desire for additionality is understandable. Developing countries need to be reassured that promises of contributions to the costs of adaptation are in fact kept and that they are additional to ODA. For their part developed countries want reassurance that the funds are indeed used for adaptation to climate change. However, the need to have additionality ingrained in adaptation institutions may create barriers to this ambition. Overcoming the fixation with additionality is, perhaps surprisingly, one of the biggest challenges for wise adaptation.

\section{Conclusions}

This paper has outlined some high-level criteria to guide adaptation decisions and ensure that adaptation financing is spent wisely. The general philosophy underlying our recommendations is one of adaptation as development, or in the words of Stern (2009) of "adaptation as development under an adverse climate". Basic development indicators like

\footnotetext{
${ }^{10}$ For an analysis of the CDM adaptation levy see Fankhauser and Martin (2010).
} 
literacy and good institutions are associated with lower vulnerability and higher adaptive capacity. A minimum level of adaptive and administrative capacity in all countries is also needed for deeper adaptations to build on. Among these subsequent steps are measures to increase response capacity to stress events in general and the ability to deal with current climate extremes.

Many of these measures are not adaptation in the traditional sense. Some, like reversing the spread of malaria, are Millennium Development Goals. However, they are classic win-win options that target the world's poor and offer immediate benefits independent of the eventual climate changes.

Priority measures also predominantly fall under the rubric of soft adaptation, that is, institutional, regulatory or behavioural responses to climate change, that are more flexible and often more cost-effective than capital investment.

The need for climate-resilient infrastructure is one area where hard adaptation may be warranted. Developing countries have massive investment needs for energy, water, transport and other infrastructure demands over the coming decades (UNFCCC 2007). Ensuring that these investments are resilient to climate change is another adaptation priority, given their multi-decade lifetimes. ${ }^{11}$ But even here the need for expensive structural measures can often be reduced through smart planning and design, as the example of the Thames Estuary shows (see footnote 4).

Another priority area where decisions taken early can have wide-ranging long-term benefits is planning, understood broadly to include urban planning, land use planning and coastal zone management, but also agricultural and industrial development. These are areas where countries otherwise risk locking themselves into a vulnerable development path. The answer is to build adaptation systematically into development plans, including national-level growth and development strategies. In doing so, adaptation is linked to poverty alleviation, which safeguards an equitable outcome.

Development organizations are doing many of these things already. Much of the current adaptation work on the ground follows the same principles, and local groups and NGOs are starting to bring adaptation to the communities. However, the emerging adaptation regime may discriminate against some aspects of this program because the proposed measures are

\footnotetext{
${ }^{11}$ Hallegatte (2009) reports time scales of 30-200 years for transport and water infrastructure, 20-70 years for energy investments and 30-150 years for buildings.
} 
less visible, less well-defined and less obviously additional than hard adaptation or independent adaptation programs.

Similarly, existing development institutions have yet to demonstrate an "adaptation mindset" that sees climate change as an integrated part of development, rather than an environmental bolt-on. They have to prove that they have the expertise, strength in depth and credibility (with both developed and developing country partners) to take on adaptation.

Wise adaptation also requires a more thorough and systematic approach to knowledge management. The Nairobi Work Programme of the UNFCCC is an important first step in this direction, but much more learning and information sharing will be required to build up a global knowledge base. There is a need to develop a community of practice on adaptation or more precisely many communities of practice for regions, different climate risks, and different sectors, supported by web based information, and facilitated through periodic meetings and conferences including at the global level. The biennial world conference on HIV - AIDS might be taken as a partial model.

Within the Convention process, there may have to be a new expert group on adaptation to synthesize knowledge and to advise the parties on all aspects of adaptation within the Convention, and on coordination with activities outside the scope of the Convention. Such an Expert Group properly constituted could build upon the activities of the Nairobi Work Programme and develop it much further. The work of the expert group would be predicated on the existence and growing strength of a global network of international centers on climate change adaptation. The CGIAR network with modifications might be considered as a possible model.

With these or similar structures in place, there would be at least a better chance that the adaptation finance promised in Copenhagen (COP 15) and as elaborated in Cancun (COP 16) will be spent wisely. 


\section{References}

Adger, N. J. Paavola, S. Huq and M.J. Mace, eds. (2006). Fairness in Adaptation to Climate Change, Cambridge MA: MIT Press.

AGF (2010). Report of the Secretary General's High Level Advisory Group on Climate Change Financing. November. http://www.un.org/wcm/content/site/climatechange/pages/ financeadvisorygroup/pid/13300.

Anderson, S., D.S. Hansen, L.G Jensen and I. Burton (2009). Evaluation of the operation of the Least Developed Countries Fund for adaptation to climate change. Joint External Evaluation, COWI Group and International Institute for Environment and Development, September.

Agrawala, S. and S. Fankhauser (2008). Economic aspects of adaptation to climate change. Costs, benefits and policy instruments. Paris: OECD.

Barr, R., S. Fankhauser and K. Hamilton (2010). "Adaptation Investments: A Resource Allocation Framework", in: Mitigation and Adaptation Strategies for Global Change, DOI: 10.1007/s11027-010-9242-1

Berang-Ford, L., J. Ford and J. Paterson (2010). "Are We Adapting to Climate Change", in : Global Environmental Change. doi:10.1016/i.gloenvcha.2010.09.012

Bird, N. and J. Brown (2010). International Climate Finance. Principles for European Support to Developing Countries. Working Paper No 6, European Development Cooperation to 2020. http://www.edc2020.eu/82.0.html.

Brooks, N., N. Adger and M. Kelly (2005). "The determinants of vulnerability and adaptive capacity at the national level and the implications for adaptation", in: Global Environmental Change 15: 151-163.

Burton, I. (2009). "Climate Change and the Adaptation Deficit", in: E.L.F. Schipper and I. Burton, eds. The Earthscan Reader on Adaptation to Climate Change, London: Earthscan

Burton, I. (2010) “Forensic Disaster Investigations in Depth",in: Environment Magazine 52. No 5. pp. 36-41.

Carpenter, K., M. Abrar, G. Aeby, R. Aronson, S. Banks, A. Bruckner, A. Chiriboga, J. Cortés, J.C. Delbeek, L. DeVantier, G. Edgar, A. Edwards, D. Fenner, H. Guzmán, B. Hoeksema, G. Hodgson, O. Johan, W. Licuanan, S. Livingstone, E. Lovell, J. Moore, D. Obura, D. Ochavillo, B. Polidoro, W. Precht, M. Quibilan, C. Reboton, Z. Richards, A. Rogers, J. Sanciangco, A. Sheppard, C. Sheppard, J. Smith, S. Stuart, E. Turak, J. Veron, C. Wallace, E. Weil and E. Wood (2008), "One-Third of Reef-Building Corals Face Elevated Extinction Risk from Climate Change and Local Impacts", in: Science 321(5888): 560 - 563.

Climate Investment Funds (2010a). Bangladesh: Strategic Programme for Climate Resilience. Document PPCR SC.7/5, Washington DC.

Climate Investment Funds (2010a). Niger: Strategic Programme for Climate Resilience. Document PPCR SC.7/6, Washington DC. 
Climate Investment Funds (2010a). Tajikistan: Strategic Programme for Climate Resilience. Document PPCR SC.7/7, Washington DC.

Dessai, S., M. Hulme, R. Lempert and R. Pielke (2009). "Climate prediction: A limit to adaptation?" in: W.N. Adger, I. Lorenzoni and K. O'Brien (eds), Adapting to Climate Change: Thresholds, Values, Governance, Cambridge: CUP.

Dell, M., B. F. Jones, and B. A. Olken (2008), Climate Change and Economic Growth: Evidence from the Last Half Century, NBER Working Papers Series, No. 14132.

Fankhauser, S. (2010). "The costs of adaptation", Wiley Interdisciplinary Review Climate Change, 1(1): 23-30.

Fankhauser, S., J. B. Smith and R. Tol (1999). Weathering Climate Change. Some Simple Rules to Guide Adaptation Investments, in: Ecological Economics, 30(1): 67-78. .

Fankhauser, S. and N. Martin (2010). "The Economics of the CDM Levy: Revenue Potential, Tax Incidence and Distortionary Effects", in: Energy Policy, 38(1).

Gollier, C. (2001). The Economics of Risk and Time. Cambridge MA: MIT Press.

Hallegatte, S. (2009). "Strategies to Adapt to An Uncertain Climate Change", in: Global Environmental Change, 19(2): 240-247.

International Development Association (2007). IDA's Performance Based Allocation Systems. Options for Simplifying the Formula and Reducing Volatility, Washington DC, The World Bank. http://siteresources.worldbank.org/IDA/Resources/Seminar\%2OPDFs/73449-11725259 76405/3492866-1172527584498/PBAformula.pdf

Klein, R. and A. Möhner (2009). „Governance limits to effective global financial support for adaptation", in: W.N. Adger, I. Lorenzoni and K. O'Brien (eds), Adapting to Climate Change: Thresholds, Values, Governance, Cambridge: CUP.

Lamb, H.H. (1988). Weather, Climate and Human Affairs, London: Routledge.

Lempert, R. and M. Collins (2007).:"Managing the Risk of Uncertain Threshold Responses: Comparison of Robust, Optimum, and Precautionary Approaches", in: Risk Analysis, 27(4), 1009-1026.

McGray, H., A. Hamill, R. Bradley, E.L. Schipper and J-O. Parry (2007). Weathering the storm. Options for framing adaptation and development. World Resources Institute, Washington DC.

Müller, B. (2010). The Reformed Financial Mechanism of the UNFCCC. Part II: The Question of Oversight, Oxford Institute of Energy Studies, EV 52, April.

Müller, B. and L. Gomez-Echeverry (2009). The Reformed Financial Mechanism of the UNFCCC. Part I: Architecture and Governance, Oxford Institute of Energy Studies, EV 45, April.

Narain, U. (2011) [this issue] 
Noy, I. (2009), "The Macroeconomic Consequences of Disasters", Journal of Development Economics, Vol. 88, pp. 221-231.

Osman-Elasha, B. and T. Downing (2007). Lessons Learned in Preparing National Adaptation Programmes of Action in Eastern and Southern Africa. European Capacity Building Initiative (ECBI), Oxford.

Pittock, B. and R. Jones (2000). "Adaptation to What and Why" in: Environmental Monitoring and Assessment 61(1): $9-35$.

Raddatz, C. (2009), "The Wrath of God: Macroeconomic Consequences of Natural Disasters", World Bank Policy Research Working Paper No. 5039, World Bank, Washington DC.

Ranger, N., A. Milner, S. Dietz, S. Fankhauser, A. Lopez and G. Ruta (2010). Adaptation in the UK: A Decision Making Process. Grantham Research Institute on Climate Change and Centre for Climate Change Economics and Policy, London School of Economics.

Schelling, T. (1992), "Some Economics of Global Warming" American Economic Review 82(1): 1-14.

Schelling, T. (1997). The Cost of Combating Global Warming: Facing the Tradeoffs, in: Foreign Affairs, 76(6): 8-14.

Solomon, S. , D. Qin, M. Manning, M. Marquis, K. Averyt, M. Tignor, H.L. Miller, and Z. Chen (2007), eds., Climate Change 2007. The Physical Science Basis. Contribution of Working Group I to the Fourth Assessment Report of the Intergovernmental Panel on Climate Change, Cambridge: CUP.

Stern, N., 2008, The Economics of Climate Change, in: American Economic Review, 98 (2), 137.

Stern, N. (2009). A Blueprint for a Greener Planet. London: The Bodley Head.

Stainforth, D, M. Allen, E. Tredger and L. Smith (2007a). "Confidence, uncertainty and decision-support relevance in climate predictions", in: Philosophical Transactions of the Royal Society A: Mathematical, Physical and Engineering Sciences, 365: 2145-2161.

Stainforth, D., T. Downing, R. Washington, A. Lopez, and M. New (2007b). "Issues in the interpretation of climate model ensembles to inform decisions", in: Philosophical Transactions of the Royal Society A: Mathematical, Physical and Engineering Sciences, 365: 2163-2177.

Swiss Re (2009). Economics of Adaptation to Climate Change. A Framework for Decision Making. http://www.swissre.com/rethinking/climate/.

Tol, R.S.J. and G.W. Yohe (2007), 'The Weakest Link Hypothesis for Adaptive Capacity: An Empirical Test', Global Environmental Change, 17: 218-227.

UNFCCC (2007). Investment and Financial Flows to Address Climate Change. United Nations Framework Convention on Climate Change, Bonn. 
Vivid Economics (2010). Climate change, adaptation and economic growth. Paper prepared for the UK Department of International Development, July.

World Bank (2010a). The Costs to Developing Countries of Adapting to Climate Change. The Global Report of the Economics of Adaptation to Climate Change Study, The World Bank, Washington DC.

World Bank (2010b). World Development Report 2010. Development and Climate Change. World Bank, Washington DC. 